\title{
Anatomia e ultraestrutura foliar de Ocimum gratissimum sob diferentes níveis de radiação luminosa
}

\section{Leaf anatomy and ultrastructure of Ocimum gratissimum under different light radiation levels}

\author{
Valéria Ferreira Fernandes ${ }^{\mathrm{I}}$ Lais de Almeida Bezerra ${ }^{\mathrm{I}}$ Marcelo Schramm Mielke \\ Delmira da Costa Silva ${ }^{\mathrm{I}}$ Larissa Corrêa do Bomfim Costa ${ }^{{ }^{*}}$
}

RESUMO

Espécies vegetais são capazes de ajustar suas características fisiológicas, anatômicas e ultraestruturais aos fatores ambientais, como, por exemplo, a disponibilidade de radiação luminosa incidente. O objetivo deste estudo foi avaliar a influência de diferentes níveis de radiação luminosa na anatomia e ultraestrutura foliar de Ocimum gratissimum $L$. (Lamiaceae). As plantas foram cultivadas por 93 dias em quatro níveis de radiação fotossinteticamente ativa $\left(20,11,7\right.$ e $4 \mathrm{~mol} \mathrm{~m} \mathrm{~m}^{-2}$ $\left.d^{-1}\right)$. O incremento da intensidade de luz proporcionou aumento no espessamento dos parênquimas paliçádico e esponjoso e do limbo foliar, entretanto, a espessura da epiderme não foi alterada. Em relação aos aspectos ultraestruturais, verificouse aumento no tamanho dos cloroplastos e grãos de amido e um aumento do empilhamento dos tilacoides com a redução da intensidade de luz. As variações anatômicas e ultraestruturais verificadas confirmam a plasticidade fenotípica dessa espécie em função da intensidade de radiação luminosa.

Palavras-chave: planta medicinal, plasticidade fenotípica, Lamiaceae.

\section{ABSTRACT}

Plant species are able to adjust their physiological, anatomical and ultrastructural characteristics to changes in environmental factors, such as the availability of incident light. The objective of this study was to evaluate the influence of different light radiation levels on leaf anatomy and ultrastructure in plants of Ocimum gratissimum L. (Lamiaceae). Plants were grown for 93 days in four levels photosynthetic active radiation (FAR): 20, 11, 7 and $4 \mathrm{~mol} \mathrm{~m} \mathrm{~m}^{-2} \mathrm{~d}^{-1}$. The increase of light intensity resulted in increase of palisade and spongy parenchyma thickness and leaf blade. However, epidermal thickness was not changed. Regarding the ultrastructural aspects, there was an increase in the size of the chloroplasts and starch granules. However, there was an increase of the stacking of the thylakoids with reducing light intensity. Anatomical and ultrastructural changes confirm the phenotypic plasticity of this species as a function of changes in light intensity.

Key-words: medicinal plant, phenotypic plasticity, Lamiaceae.

\section{INTRODUÇÃO}

Ocimum gratissimum L. é um subarbusto aromático pertencente à família Lamiaceae, originária da Ásia e África do Sul, mas de ocorrência espontânea em todo o território brasileiro. No Brasil, essa espécie é conhecida popularmente como alfavaca e possui óleo essencial rico em eugenol (SARTORATTO et al., 2004), com propriedades antifúngica (FARIA et al., 2006) e antioxidante (TREVISAN et al., 2006) comprovadas.

A estrutura foliar pode ser alterada pela radiação luminosa incidente durante o desenvolvimento das folhas e, geralmente, são observadas variações anatômicas e ultraestruturais, que se constituem em aspectos decisivos de aclimatação ao ambiente (LAMBERS et al., 2008). As folhas que se desenvolvem sob altas intensidades de radiação luminosa geralmente apresentam maior espessamento do limbo foliar, devido, principalmente, ao aumento da espessura do parênquima paliçádico (LAMBERS et al., 2008), como verificado, por exemplo, em Bauhinia forficata e Maytenus ilicifolia, cultivadas a pleno sol (BOEGER et al., 2009). Além das alterações nos tecidos fotossintetizantes do mesofilo, também podem ser observadas variações ultraestruturais no tamanho dos cloroplastos e no empilhamento dos tilacoides (KIERZKOWSKI et al., 2007; LAMBERS et al., 2008).

Estudos que relacionam características anatômicas e ultraestruturais de espécies medicinais podem fornecer subsídios para o conhecimento das

IUniversidade Estadual de Santa Cruz (UESC), 45662-900, Ilhéus, BA, Brasil. E-mail: larissa@uesc.br. *Autor para correspondência. Recebido 21.03.13 Aprovado 02.12.13 Devolvido pelo autor 30.03.14 CR-2013-0387.R3 
condições ideais de cultivo (BOEGER et al., 2009; MARTINS et al., 2010), bem como verificar as respostas das plantas às variações ambientais. Neste estudo, objetivou-se avaliar o efeito de diferentes intensidades de radiação luminosa sobre a anatomia e ultraestrutura foliar de $\boldsymbol{O}$. gratissimum.

\section{MATERIAL E MÉTODOS}

As mudas foram obtidas por propagação vegetativa de estacas de caule basais com aproximadamente dez centímetros de comprimento. Uma exsicata do material está depositada no herbário da HUESC sob o número 14.427. Após o enraizamento, as mudas foram transplantadas para vasos contendo 10L de substrato na proporção $3: 1: 1$ (solo:esterco:areia) e submetidas a quatro ambientes de radiação luminosa (T1, T2, T3 e T4), obtidos pela cobertura com telas pretas. $\mathrm{T} 1$ correspondeu às condições naturais de radiação luminosa do viveiro que mede $15 \mathrm{mx} 20 \mathrm{~m}$, coberto por tela que proporciona $25 \%$ de atenuação da radiação luminosa e dentro do qual foram colocadas três estruturas individuais menores $(4,3 \times 1,6 \times 1,2 \mathrm{~m})$, também cobertas com telas pretas $(25,50$ e $75 \%$ de atenuação da radiação luminosa), constituindo os ambientes T2, T3 e T4, respectivamente.

Durante todo o período de execução do experimento (04/10/10 a 04/01/11), a radiação fotossinteticamente ativa (RFA) foi monitorada em cada ambiente por meio de sensores de radiação luminosa S-LIA-M003, acoplados a uma estação climatológica Hobo Micro Station Data Logger (Onset Computer, Massachusetts, USA) e programados para realizarem leituras em intervalos de um minuto, armazenando uma leitura a cada dez minutos. As médias diárias da radiação fotossinteticamente ativa (RFA) registradas no período para cada tratamento foram de 20, 11, 7 e $4 \mathrm{~mol} \mathrm{~m} \mathrm{~m}^{-2} \mathrm{~d}^{-1}$ para $\mathrm{T} 1, \mathrm{~T} 2$, T3 e $\mathrm{T} 4$, respectivamente.

Porções da região mediana foliar do terceiro nó do ápice para a base, de quatro repetições de cada tratamento, foram fixadas em glutaraldeído $2,5 \% \mathrm{em}$ tampão cacodilato de sódio $0,1 \mathrm{M}, \mathrm{pH} 6,9$ por 4 horas, pós-fixadas com tetróxido de ósmio $1 \%$, desidratadas em série etanólica crescente, infiltradas em resina LRWhite. Para o estudo anatômico, secções transversais foram obtidas em ultramicrótomo (LEICA EM UC 6, Vienna, Austria) e coradas com azul de toluidina a $1 \%$. As análises e a documentação fotográfica foram realizadas em microscópio invertido (DMI 3000 B, Wetzlar, Germany) com câmera digital acoplada. Para cada tratamento, foram observados dez campos em cada repetição, totalizando quarenta observações, e as variáveis analisadas foram: espessura da face adaxial (EAD) e face abaxial (EAD) da epiderme, parênquima paliçádico (PP), parênquima esponjoso (PE), razão parênquima paliçádico e esponjoso (PP/ $\mathrm{PE}$ ) e limbo foliar (L) utilizando o software Leica application suite V3.

No estudo ultraestrutural, secções de 70$90 \mathrm{~nm}$ foram contrastadas com acetato de uranila $2 \%$ e citrato de chumbo (REYNOLDS, 1963). As análises foram realizadas em microscópio eletrônico de transmissão MORGAGNI $268 \mathrm{D}$, em 80KV, com câmera digital acoplada. As características ultraestruturais foram observadas a partir de vinte observações por tratamento.

O delineamento experimental utilizado foi o inteiramente casualizado e os dados obtidos foram submetidos à análise de variância e a comparação das médias foi feita pelo teste de Tukey a 5\% de probabilidade, utilizando-se o programa estatístico SISVAR 5.3 (FERREIRA, 2000).

\section{RESULTADOS E DISCUSSÃO}

Em secção transversal, a lâmina foliar de $\boldsymbol{O}$. gratissimum possui epiderme unisseriada, com células da face adaxial maiores em relação às da face abaxial (Figura 1). A espessura da epiderme não foi alterada pelos níveis de radiação luminosa (Tabela 1), entretanto, isso pode ser variável conforme a espécie. Folhas de Mikania glomerata, cultivadas sob diferentes condições de luminosidade, não apresentaram diferença significativa na espessura da epiderme (ESPINDOLA JUNIOR et al., 2009), enquanto em folhas de Aloysia gratissima (PINTO et al., 2007), a espessura da epiderme de ambas as faces foi alterada sob condições de sombreamento.

O mesofilo do tipo dorsiventral de $\boldsymbol{O}$. gratissimum é constituído por uma camada de parênquima paliçádico e três a quatro de parênquima esponjoso, que apresentou visualmente aumento dos espaços intercelulares, com a redução da radiação luminosa (Figura 1). O espessamento do parênquima paliçádico, verificado em função dos tratamentos, foi resultante do alongamento celular, uma vez que o número de camadas desse tecido mantevese inalterado. Segundo BOEGER et al. (2009) e LAMBERS et al. (2008), o aumento da espessura do parênquima paliçádico, observado em condições de exposição a maiores níveis de radiação, pode ser tanto devido à adição de novas camadas de parênquima paliçádico, quanto pelo alongamento de células ou pela combinação desses dois fatores. As células do 


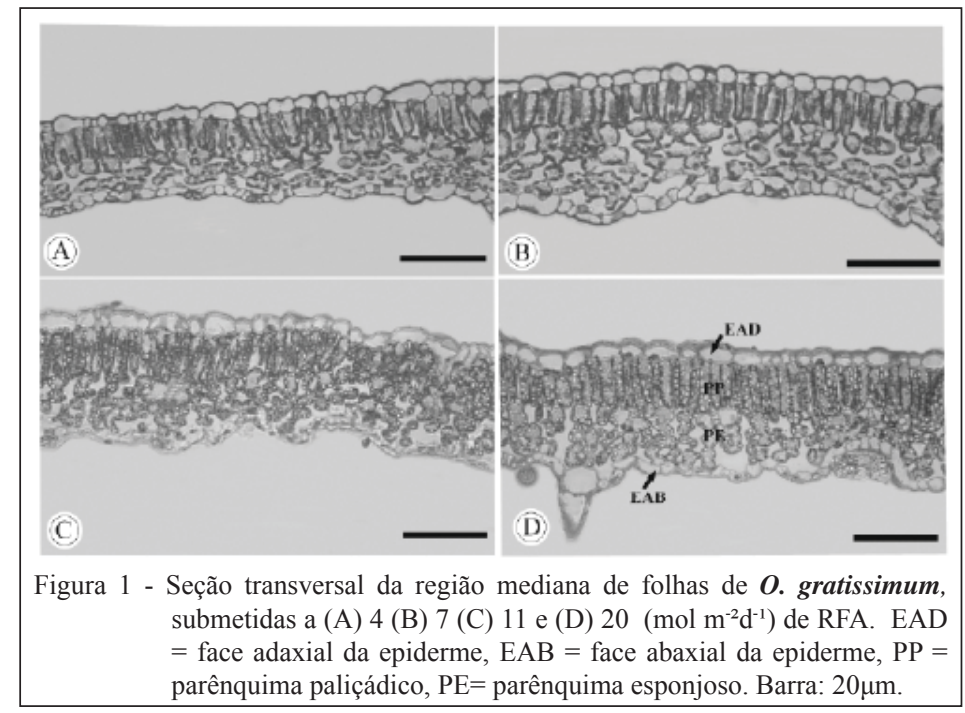

parênquima paliçádico apresentam formato colunar a fim de canalizar a luz incidente e, geralmente, observase que folhas que se desenvolvem em ambientes sob intensa radiação luminosa, apresentam maior espessura do parênquima paliçádico (VOGELMAN et al., 1996).

Observou-se uma redução significativa na espessura dos parênquimas paliçádico e esponjoso dos tratamentos mais sombreados em relação ao tratamento de $20 \mathrm{~mol} \mathrm{~m}^{-2} \mathrm{~d}^{-1}$ (Tabela 1). Em Aloysia gratissima, também foi observada maior espessura do parênquima esponjoso no tratamento com maior intensidade de radiação luminosa (PINTO et al., 2007). De acordo com YANO \& TERASHIMA (2001), o arranjo irregular das células do parênquima esponjoso conduz a um percurso mais efetivo de dispersão da luz no mesofilo. Esse fato implica uma maior quantidade de luz interceptada por unidade de clorofila nas suas células e explica o maior espessamento desse tecido nas folhas das plantas cultivadas em ambientes com menor disponibilidade de radiação luminosa. Em condições de elevada irradiância, as plantas otimizam o uso da energia da luz para a fotossíntese (capacidade fotossintética) e dissipação, enquanto, de baixa irradiância, as plantas maximizam a captura de luz (VALLADARES et al., 2012).

O maior espessamento do limbo foliar no tratamento de maior intensidade de radiação luminosa está relacionado com o aumento das espessuras dos parênquimas paliçádico e esponjoso (Tabela 1). De forma geral, verifica-se que folhas de sol possuem maior espessura do limbo foliar (SCHULZE et al., 2005), conforme observado em Vaccinium corymbosum cv. Bluecrop (KIM et al., 2011) e Aloysia gratissima (PINTO et al., 2007). Folhas que se desenvolveram em ambientes com alta luminosidade tendem a ser menores e mais espessas, apresentando mesofilo compacto com espaços

Tabela 1 - Espessura $(\mu \mathrm{m})$ média e respectivos desvios padrão $( \pm)$ dos componentes foliares anatômicos de $\boldsymbol{O}$. gratissimum cultivada sob diferentes níveis de radiação luminosa $(\mathrm{n}=4)$. $\mathrm{EAD}=$ face adaxial da epiderme, $\mathrm{EAB}=$ face abaxial da epiderme; $\mathrm{PP}=\mathrm{parênquima}$ paliçádico; $\mathrm{PE}=$ parênquima esponjoso; $\mathrm{PP} / \mathrm{PE}=$ razão do parênquima paliçádico e esponjoso; e $\mathrm{L}=$ limbo foliar.

\begin{tabular}{|c|c|c|c|c|}
\hline Variáveis & 4 & 7 & 11 & 20 \\
\hline EAD & $15,27 \pm 2,24 a$ & $15,18 \pm 1,28 \mathrm{a}$ & $17,06 \pm 1,40 \mathrm{a}$ & $17,74 \pm 1,43 \mathrm{a}$ \\
\hline EAB & $10,99 \pm 0,96 a$ & $11,13 \pm 1,32 \mathrm{a}$ & $11,92 \pm 2,09 \mathrm{a}$ & $11,70 \pm 1,42 \mathrm{a}$ \\
\hline PP & $31,62 \pm 4,49 b$ & $35,63 \pm 4,90 b$ & $40,45 \pm 3,50 b$ & $50,06 \pm 4,46 \mathrm{a}$ \\
\hline PE & $45,93 \pm 7,45 b$ & $54,86 \pm 8,83 \mathrm{ab}$ & $44,16 \pm 4,47 b$ & $64,48 \pm 11,27 \mathrm{a}$ \\
\hline $\mathrm{PP} / \mathrm{PE}$ & $0,71 \pm 0,08 \mathrm{ab}$ & $0,68 \pm 0,03 b$ & $0,92 \pm 0,03 \mathrm{a}$ & $0,81 \pm 0,13 \mathrm{ab}$ \\
\hline $\mathrm{L}$ & $104,20 \pm 12,21 b$ & $117,17 \pm 9,37 b$ & $113,47 \pm 8,41 b$ & $143,16 \pm 13,42 \mathrm{a}$ \\
\hline
\end{tabular}

Médias seguidas de mesma letra na linha não diferem entre si pelo teste de Tukey em nível de 5\% de probabilidade.

Ciência Rural, v.44, n.6, jun, 2014. 
intercelulares reduzidos. Essas variações estruturais estão relacionadas com a regulação da radiação luminosa e difusão de $\mathrm{CO}_{2}$, proporcionando uma maior eficiência fotossintética (DICKISON, 2000; VALLADARES et al., 2012).

Diferenças ultraestruturais entre cloroplastos de plantas de sol e de sombra são amplamente relatadas na literatura (ANDERSON, 1986; YANO \& TERASHIMA, 2001). Cloroplastos de plantas de sol apresentam tilacoides pouco compactos e maior número de lamelas no estroma, enquanto que os cloroplastos de plantas de sombra são caracterizados pela maior compactação dos tilacoides e amplas pilhas de grana (ANDERSON, 1986). O tamanho dos cloroplastos e grãos de amidos de $\boldsymbol{O}$. gratissimum foi mais acentuado no tratamento de $20 \mathrm{~mol} \mathrm{~m}^{-2} \mathrm{~d}^{-1}$ (Figura 2). Nas espécies Calophyllum brasiliense (NERY et al., 2007) e Coffea arabica (GOMES et al., 2008), também ocorreu um aumento do tamanho dos cloroplastos em maiores intensidades de radiação luminosa, bem como do tamanho dos grãos de amido na espécie $\boldsymbol{A} \boldsymbol{b i e s}$ alba (KIERZKOWSKI et al., 2007). Grãos de amido maiores estão associados com uma fotossíntese mais intensa nos cloroplastos de plantas mantidas sob maiores intensidades de radiação luminosa (ROBAKOWSKI et al., 2004).

Observou-se granum mais espesso com empilhamento de tilacoides mais compacto nas condições de menor disponibilidade de radiação luminosa (Figura 3). Em geral, verifica-se maior empilhamento em níveis menores de radiação luminosa. Dessa forma, o granum é mais desenvolvido nas folhas sob baixa intensidade de radiação luminosa (SCHULZE et al., 2005), proporcionando maior produção de clorofila em plantas sombreadas (LAMBERS et al., 2008). Resultado similar foi encontrado em Abies alba (KIERZKOWSKI et al., 2007). A ocorrência de plastoglóbulos parece ter aumentado nas plantas de $\boldsymbol{O}$. gratissimum submetidas a maiores intensidades de radiação luminosa (Figura 3). Isso pode estar relacionado com o estresse oxidativo no aparato fotossintético em decorrência de fatores ambientais, como o aumento da intensidade de radiação luminosa, como um mecanismo de defesa para evitar possíveis danos ao aparato fotossintético (AUSTIN et al., 2006).

\section{CONCLUSÃO}

Foi constatada a capacidade de aclimatação de Ocimum gratissimum em diferentes níveis de radiação luminosa através das modificações anatômicas, principalmente na espessura dos parênquimas paliçádico e esponjoso. Além disso, foram observadas alterações ultraestruturais no tamanho dos cloroplastos e dos grãos de amido, no empilhamento dos cloroplastos e na ocorrência de plastoglóbulos.

\section{AGRADECIMENTOS}

À Coordenação de Aperfeiçoamento de Pessoal de Nível Superior (CAPES), pela concessão da bolsa de estudo

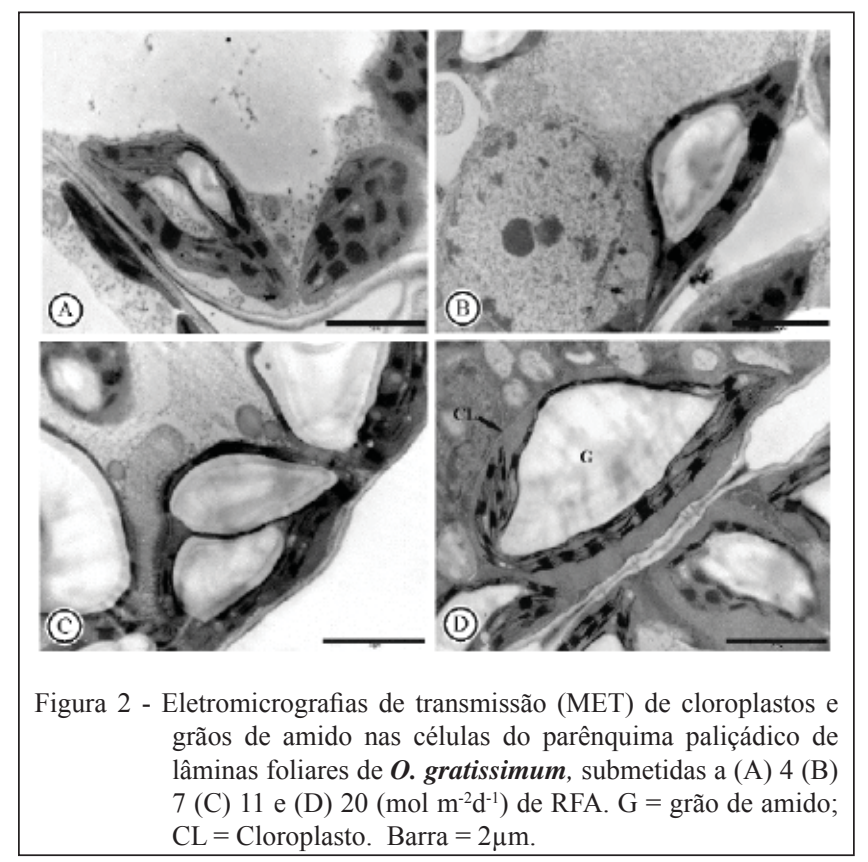

Ciência Rural, v.44, n.6, jun, 2014. 


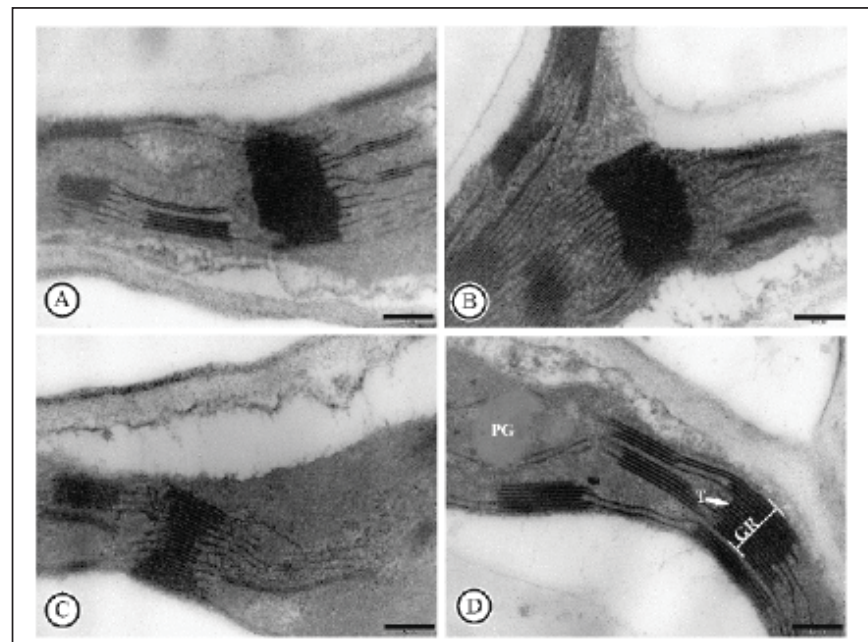

Figura 3 - Detalhe dos cloroplastos nas células do parênquima paliçádico de lâminas foliares de $\boldsymbol{O}$. gratissimum, submetidas a (A) 4 (B) 7 (C) 11 e (D) $20\left(\mathrm{~mol} \mathrm{~m}^{-2} \mathrm{~d}^{-1}\right)$ de RFA, evidenciando os $\mathrm{PG}=$ plastoglóbulos, $\mathrm{T}=$ tilacoides e $\mathrm{GR}=$ granum. Barra $=2 \mu \mathrm{m}$.

da primeira autora. Aos professores Eduardo Gross e Pedro Mangabeira do Centro de Microscopia Eletrônica da UESC, pelos auxílios na análise ultraestrutural. Ao Conselho Nacional de Desenvolvimento Científico e Tecnológico $(\mathrm{CNPq})$, pela concessão das bolsas de Produtividade aos pesquisadores Delmira da Costa Silva e Marcelo Schramm Mielke.

\section{REFERÊNCIAS}

ANDERSON, J.M. Photoregulation of the composition, function, and structure of thylakoid membranes. Annals Review of Plant Physiology, v.37, p.93-136, 1986. Disponível em: $\quad<$ http://www.annualreviews.org/doi/pdf/10.1146/annurev. pp.37.060186.000521>. Acesso em: 16 jul. 2013.

AUSTIN, J.R. et al. Plastoglobules are lipoprotein subcompartments of the chloroplast that are permanently coupled to thylakoid membranes and contain biosynthetic enzymes. Plant Cell, v.18, p.1693-1703, 2006. Disponível em: <hppt://http:// www.plantcell.org/content/18/7/1693.full.pdf + html $>$. Acesso em: 01 jul. 2013. doi: $101105 /$ tcp. 105.039859 .

BOEGER, M.R.T. et al. Variação estrutural foliar de espécies medicinais, em consórcio com erva-mate, sob diferentes intensidades luminosas. Revista Científica Eletrônica de Engenharia Florestal, v.39, p.215-225, 2009. Disponível em: <http://ojs.c3sl.ufpr.br/ojs/ índex.php/floresta/article/view/13741/9262>. Acesso em: 06 jan.10.

DICKISON, W.C. Integrative plant anatomy. San Diego: Academic, 2000. 532p.

ESPINDOLA JUNIOR, A. et al. Variação na estrutura foliar de Mikania glomerata Spreng. (Asteraceae) sob diferentes condições de luminosidade. Revista Brasileira de Botânica, v. 32, p. 749 758, 2009. Disponível em: <http://www.scielo.br/pdf/rbb/v32n4/ a13v32n4.pdf>. Acesso em: 26 jun. 2013.

FARIA, T.J. et al. Antifungal activity of essential oil isolated from Ocimum gratissimum L. (eugenol chemotype) against phytopathogenic fungi. Brazilian Archives of Biology and
Technology, v. 49, p. 867-871, 2006. Disponível em: <http://www. scielo.br/pdf/babt/v49n6/a02v49n6>. Acesso em: 05 fev. 2014.

FERREIRA, D.F. Análises estatísticas por meio do Sisvar para Windows versão 4.0. São Carlos, SP, 2000. In: REUNIÃO ANUAL DA REGIÃO BRASILEIRA DA SOCIEDADE INTERNACIONAL DE BIOMETRIA, 45., 2000, São Carlos, SP. Anais... São Carlos : UFSCar, 2000 p.255-258.

GOMES, I.A.C. et al. Alterações morfofisiológicas em folhas de Coffea arabica L. cv. "Oeiras" sob influência do sombreamento por Acacia mangium Willd. Ciência Rural, v.38, p.109115, 2008. Disponível em: <http://dx.doi.org/10.1590/S010384782008000100018>. Acesso em: 02 set. 2011. doi: 10.1590/ S0103-84782008000100018.

YANO, S.; TERASHIMA, I. Separate localization of light signal perception for sun or shade type chloroplast and palisade tissue differentiation in Chenopodium album. Plant and Cell Physiology, v.42, n.12, p.1303-1310, 2001. Disponível em: $<$ http:// pcp.oxfordjournals.org/content/42/12/1303.full.pdf + html $>$. Acesso em: 16 jul. 2013. doi: 10.1093/pcp/pce18.

KIERZKOWSKI, D. et al. Variation in ultrastructure of chloroplast in needles of silver fir (Abies alba Mill.) saplings growing under the canopies of diverse tree species. Polish Journal of Ecology, v.55, n.4, p.821-825, 2007. Disponível em: <http://www.pol.j.ecol. cbe-pan.pl/article/ar55_4_16.pdf $>$. Acesso em: 21 mar. 2013.

KIM, S.J. et al. Growth and photosynthetic characteristics of blueberry (Vaccinium corymbosum cv. Bluecrop) under various shade levels. Scientia Horticulturae, v.129, p.486-492, 2011. Disponível em: <http://dx.doi.org/10.1016/j.scienta.2011.04.022>. Acesso em: 03 dez. 2010. doi:10.1016/j.scienta.2011.04.022.

LAMBERS, H. et al. Plant physiological ecology. 2.ed. New York: Springer, 2008. 610p.

MARTINS, J.R. et al. Teores de pigmentos fotossintéticos e estrutura de cloroplastos de Alfavaca-cravo. Ciência Rural, v.40, 
n.1, p.64-69, 2010. Disponível em: <http://dx.doi.org/10.1590/ S0103-84782010000100011>. Acesso em: 07 mar. 2010. doi: 10.1590/S0103-84782010000100011.

NERY, F.C. et al. Aspectos anatômicos de folhas de plantas jovens de Calophyllum brasiliense Cambess. submetidas a diferentes níveis de sombreamento. Revista Brasileira de Biociências, v.5, p.129-131, 2007. Disponível em: <http://www.ufrgs.br/seerbio/ ojs/ index.php/rbb/article/view/151/140>. Acesso: 10 jan. 2010.

PINTO, J.E.B.P. et al. Aspectos morfológicos e conteúdo de óleo essencial de plantas de alfazema-do-Brasil em função de níveis de sombreamento. Horticultura Brasileira, v.25, p.210214, 2007. Disponível em: <http://dx.doi.org/10.1590/S010205362007000200016>. Acesso em: 10 dez. 2010. doi: 10.1590/ S0102-05362007000200016.

REYNOLDS, E.S. The use of lead citrate at high $\mathrm{pH}$ as an electronopaque stain in electron microscopy. Journal of Cell Biology, v17, p.208-212, 1963. Disponível em: <http://www.ncbi.nlm.nih. gov/pmc/articles/PMC2106263/>. Acesso em: 30 jun. 2013.

ROBAKOWSKI, P. et al. Growth, diurnal photosynthesis and needle structure of silver fir (Abies alba Mill.) seedlings growing under different canopies. Forest Ecology Management, v.201, p.211-227, 2004. Disponível em: <http://ac.els-cdn.com/ S0378112704005262/1-s2.0-S0378112704005262-main.pdf? tid=23bffe 6 a-ee 1 d-11e2-944c-00000aacb35f\&acdnat $=137398 \overline{2}$
149 7767fc2ca586da53118e9b96686b3674. Acesso em: 16 abr. 2011. doi:10.1016/j.foreco.2004.06.029.

SARTORATTO, A. et al. Composition and antimicrobial activity of essential oils from aromatic plants used in Brazil. Brazilian Journal of Microbiology, v.35, p.275-280, 2004. Disponível em: $<$ http://dx.doi.org/10.1590/S1517-83822004000300001>. Acesso em: 14 abr. 2011. doi: 10.1590/S1517-83822004000300001.

SCHULZE, D-E. et al. Plant ecology. Berlin/Heidelberg: Springer, 2005. $702 p$.

TREVISAN, M.T.S. et al. Characterization of the volatile pattern and antioxidant capacity of essential oils from different species of the genus Ocimum. Journal of Agricultural and Food Chemistry, v.54, p.4378-4382, 2006. Disponível em: <http:// pubs.acs.org/doi/abs/10.1021/jf060181\%2B>. Acesso em: 10 out. 2011. doi:10.1021/jf060181+.

VALLADARES, F. et al. Photosynthetic responses to radiation. In: FLEXAS et al. Terrestrial photosynthesis in a changing environment: a molecular, physiological and ecological approach. United Kigdom: Cambridge University, 2012. Cap.16, p.241-260.

VOGELMAN, T.C. et al. Leaves and light capture: light propagation and gradients of carbon fixation within leaves. Trends in Plant Science, v.1, p.65-70, 1996. Disponível em: <http:// www.sciencedirect.com/science/article/pii/S1360138596800318>. Acesso em: 10 out. 2011. doi: 10.1016/S1360-1385(96)80031-8. 